\title{
Clinical experience with the use of two diphosphonates in the treatment of Paget's disease
}

\author{
P DEWIS, B K PRASAD, D C ANDERSON, AND S WILLETS
}

From the Department of Medicine, Hope Hospital (University of Manchester School of Medicine), Eccles OlФ Road, Salford M6 8HD, and the Department of Chemical Pathology, District and General Hospitat Ormskirk

SUMMARY The effects of EHDP (20 mg/kg/day) and APD $(4.5 \mathrm{mg} / \mathrm{kg} /$ day) given for three months to patients with severe symptomatic Paget's disease have been compared in an open triab of 17 patients. Both drugs were equally effective in producing a prompt reduction in pain score + urine hydroxyproline, and serum alkaline phosphatase levels. The remission was maintained for variable period after stopping treatment. Both drugs were well tolerated, and a one-month course of either drug was not effective. Comparison with published responses from previous studies indicates that EHDP given at this dose as a relatively short course is more effective than lower dose for a longer period of time; the present study does not suggest that APD has significant advantages.

Paget's disease of bone is a common condition in Britain, ${ }^{1}$ which often causes bone pain and has a number of serious complications, including deafness and spinal cord compression. Limited success has been obtained with calcitonin injections against bone pain and in partially correcting some of the other complications. However, the response has not been complete, and relapse occurs whenever the drug is stopped. ${ }^{2}$ Calcitonin has to be given by injection, and side effects are common. The drug ethane-1-hydroxy-1,1-diphosphonate (EHDP, etidronic acid, Didronel) has recently become available in this country, bringing with it the promise of improved pain relief for patients with Paget's disease.

EHDP is one of a number of diphosphonate compounds which are similar in structure to inorganic pyrophosphate. They inhibit the transformation of amorphous calcium phosphate into hydroxyapatite crystals, thus preventing mineralisation, ${ }^{3}$ but more importantly they inhibit bone resorption. ${ }^{4}$

This action on bone resorption is the basis of the beneficial effect of EHDP in Paget's disease. Prompt reduction in bone pain and in the levels of

Accepted for publication 20 June 1984.

Correspondence to Dr P Dewis, Department of Medicine, Clinical Sciences Building, Hope Hospital, Eccles Old Road, Salford M6 8HD. urine hydroxyproline excretion and serum alkaling phosphatase have been reported. ${ }^{56}$ Most worke recommend a dose of $5 \mathrm{mg} / \mathrm{kg} /$ day for six months? On this dose $60 \%$ of patients will improve clinicall $\vec{B}$ The serum alkaline phosphatase and urine hydrox proline fall to about $50 \%$ of their original value, and many patients remain in remission for sever: months after stopping treatment. ${ }^{5}$ At higher doses the return of bone pain associated with the histolo gical changes of osteomalacia has been reported. ${ }^{5}$; Amino-1-hydroxypropane-1,1-diphosphonate (aninohydroxy propylidene diphosphonate) (APD) is related drug which has been reported to have a more potent effect on increased bone resorption but is less likely to inhibit mineralisation. ${ }^{8}$ This drug is n generally available in Great Britain, but its effects Paget's disease have been studied by Bijvoet ar colleagues in Holland. They suggest that it is more effective than EHDP and that it does not caus osteomalacia. ${ }^{9} 10 \mathrm{~A}$ third diphosphonate, dichlor $\mathcal{E}^{2}$ methane diphosphonate, has also been used wi success in Paget's disease. ${ }^{11}{ }^{12}$ This drug was her back from the market because of reports of its being associated with acute myeloid leukaemia. ${ }^{13}$ These reports have not subsequently been substantiated.

We have recently studied the effect of $20 \mathrm{mg} / \mathrm{k}$ day of EHDP, given for three months, and have compared this with the effect of APD $(15 \mu \mathrm{mol} / \mathrm{k} g$ day) also for three months. We report the results 
Table 1 Mean age, basal serum alkaline phosphatase, and urine hydroxyproline/creatinine ratio in the two groups of patients

\begin{tabular}{llll}
\hline & Mean Age & Mean AP & Mean HOP/creat \\
\hline $\begin{array}{l}\text { Group 1 (EHDP) } \\
\mathrm{n}=11 \text { (7F, 5M) }\end{array}$ & $\begin{array}{l}68 \cdot 85 \mathrm{yr} \\
\text { (range 60-87) }\end{array}$ & $\begin{array}{l}688 \cdot 1 \text { IU/I* } \\
\text { (range 172-1820) }\end{array}$ & $\begin{array}{l}0 \cdot 113^{*} \mathrm{q} \\
(\text { range } 0 \cdot 943-0 \cdot 273)\end{array}$ \\
$\begin{array}{l}\text { Group 2 (APD) } \\
\mathrm{n}=5 \text { (3F, 2M) }\end{array}$ & $\begin{array}{l}69 \cdot 19 \mathrm{yr} \\
\text { (range 59-75) }\end{array}$ & $\begin{array}{l}959 \cdot 2 \text { IU/I* } \\
\text { (range 232-1490) }\end{array}$ & $\begin{array}{l}0 \cdot 219^{*} \\
(\text { range } 0 \cdot 078-0 \cdot 415)\end{array}$
\end{tabular}

${ }^{*}$ Differences not significant (Wilcoxon rank sum test).

an open trial of these two treatments in 17 patients with severe Paget's disease.

\section{Patients and methods}

Patients with bone pain due to Paget's disease were accepted for the trial. Many had previously had calcitonin, but none were on any other treatment for Paget's disease during the course of diphosphonate therapy or in the follow-up period. Before treatment the patients were asked to assess the severity of their pain on a visual analogue scale $(0=$ no pain, $100=$ pain as bad as can be). Blood was taken for estimations of serum alkaline phosphatase (AP), and a fasting specimen of urine was collected for measurement of the hydroxyproline:creatinine ratio (HOP/creat). A radioisotope bone scan was performed, and affected bones were $x$-rayed. Patients were then randomly allocated to one or two treatment groups. Group 1 received EHDP capsules 20 $\mathrm{mg} / \mathrm{kg} /$ day as a single daily dose, while group 2 received APD liquid $15 \mu \mathrm{mol} / \mathrm{kg} /$ day $(\simeq 4.5 \mathrm{mg} / \mathrm{kg} /$ day), taken twice daily. APD (gift from Dr Bijvoet) was made up in a liquid form. It was not possible to perform the study double-blind because we were unable to obtain APD in capsule form. Nine patients were allocated randomly to either group 1 or group 2. Two patients were put directly on APD because of osteolytic Paget's disease, while six were put directly on EHDP, either because of dyspepsia or unwillingness to take part in the trial. Patients were instructed to take the diphosphonate $1 \frac{1 / 2}{2}$ hours after and $1 \frac{1}{2}$ hours before a meal and not to take it with milk. Treatment was continued for three months, with repeat clinical and biochemical assessment at $1,2,3,4,6,9$, and 12 months after the start of treatment. On the basis of the results obtained two additional patients were treated for one month only (one with EHDP and one with APD). Blood was taken regularly throughout the trial for assessment of liver function, white cell count, haemoglobin, and platelet count.

\section{Results}

Mean ages, basal serum AP, and urine HOP/creat of the two groups are shown in Table 1 . The mean ages in groups 1 and 2 were similar, 68.9 and 69.2 years respectively. Group 2 had higher levels of AP (959 vs. $688 \mathrm{IU} / 1)$ and urine $\mathrm{HOP} /$ creat $(0 \cdot 22$ vs. $0 \cdot 11)$, though the difference was not significant. The clinical response to treatment is shown in Fig. 1. A

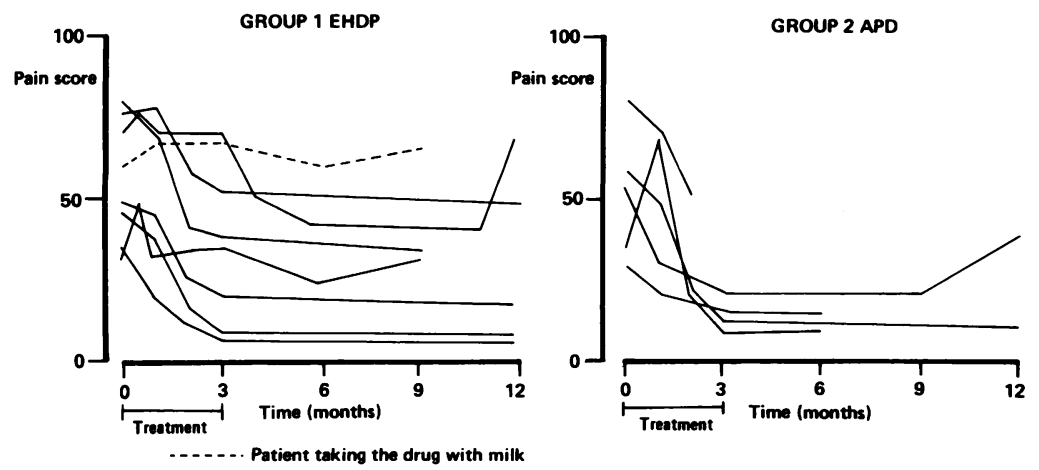

Fig. 1 Clinical responses to treatment with EHDP (group 1) and $A D P$ (group 2) as assessed by visual analogue scale. 

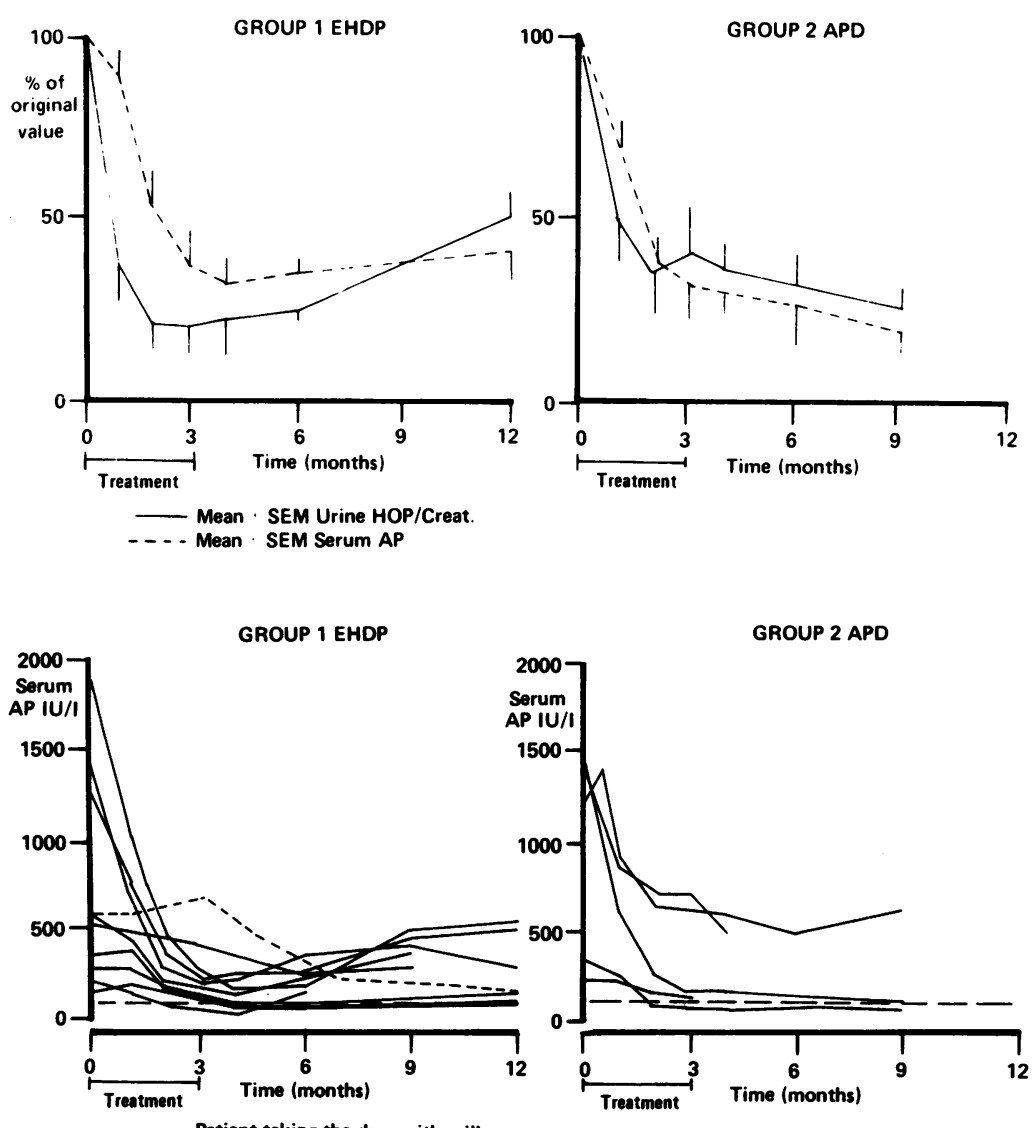

. . . - Patient taking the drug with milk
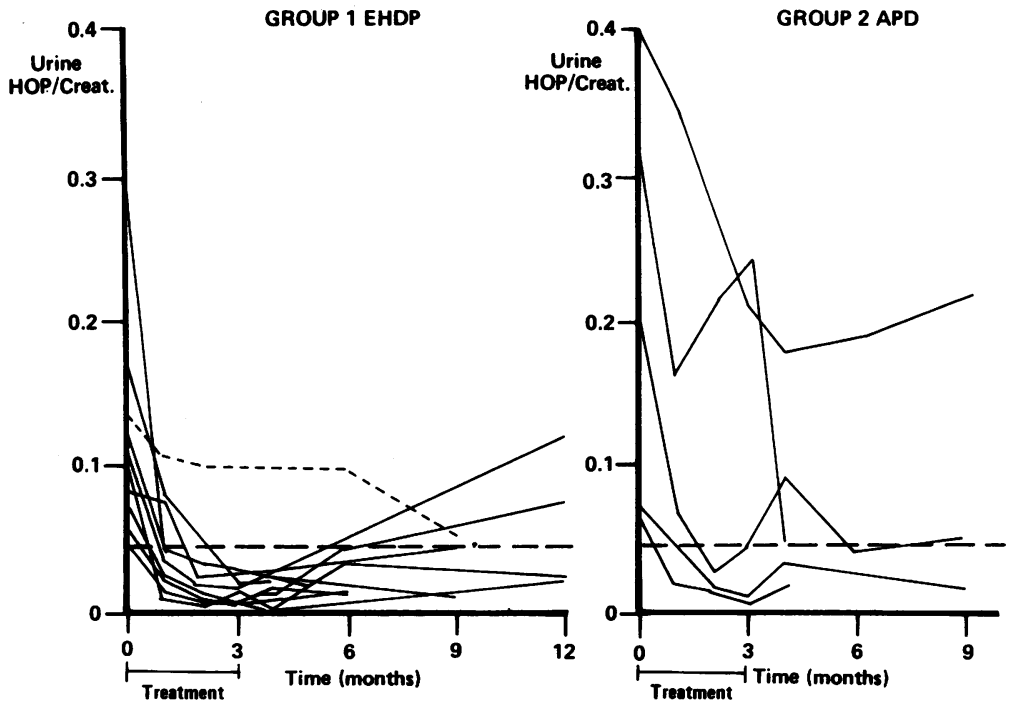

Fig. 2 Mean $\pm S E M$ serum $A P$ है and urine $H O P /$ creat in response totreatment with EHDP (group 1) and $A P D$ (group 2).

Fig. 3 Individual serum AP levelsor in response to EHDP (group 1) and APD (group 2). (The

horizontal dashed lines indicate the upper end of the normal range).

Fig. 4 Individual urine $\mathrm{HOP} /$ creat in response to EHDP (group 1) and APD (group 2). (The horizontal dashed lines indicate the् upper end of the normal range). 
prompt reduction in the severity of the pain occurred in all patients except one in group 1 and in all patients in group 2. It was later found that the patient in group 1 who did not respond to treatment had been taking the EHDP with milk and so was probably not absorbing the drug. She was given a further three-month course of treatment, when she took the drug correctly. In two patients in group 1 , after an initial improvement the pain stabilised at a relatively high level. In one of these patients the main cause of the residual pain was thought to be intermittent claudication and in the other osteoarthrosis. Mean \pm SEM serum AP and urine HOP/ creat are shown in Fig. 2. There was a prompt fall in both parameters to between 20 and $40 \%$ of the initial value in both groups. For each group as a whole the remission was maintained for nine months after stopping the drugs. However, a more accurate idea of the nature of response can be obtained by looking at individual biochemical responses (Figs. 3 and 4). For both drugs it was seen that in some patients both biochemical parameters were suppressed to normal levels and the remission was maintained for the duration of the study. The remainder of the patients showed a significant fall in $\mathrm{AP}$ and urine HOP/creat but not to normal levels. After a variable period these parameters started to rise. Patients who had biochemically severe Paget's disease at the start of the study tended to respond in this way. No radiological improvement was seen in affected bones during the study.

Both drugs were generally well tolerated. On EHDP two patients stopped treatment before the end of the three months, one because of nausea and the other because of sweating attacks. The patient who experienced nausea later developed the same symptoms on APD but the other tolerated APD well. Two patients sustained fractures through Pagetic bone. Both of these were associated with trauma and in one case occurred five months after the end of therapy. No episodes of increased bone pain or non-traumatic fracture occurred. One patient had to stop APD after two weeks because of dyspepsia. It was discovered that he had been given too high a dose. He later tolerated EHDP. One patient, who had been free of side effects of EHDP, developed dyspepsia on APD. Pyrexia did not occur with APD. No haematological disturbance or change in liver function tests occurred during treatment with either drug.

\section{Discussion}

At present the dose of EHDP recommended by the manufacturers is $5 \mathrm{mg} / \mathrm{kg} /$ day given for six months. In studies where this regimen was used about $60 \%$ of patients showed clinical improvement, and biochemical parameters fell to about $50 \%$ of the pretreatment values. ${ }^{5}$ At higher doses increased bone pain occurred, and this was associated with histological osteomalacia. ${ }^{5}$ We found that on 20 $\mathrm{mg} / \mathrm{kg} /$ day all patients responded when taking the drug properly and that the mean AP and urine $\mathrm{HOP} / \mathrm{creat}$ fell to a mean of $32 \%$ and $28 \%$ of control levels respectively. No episodes of increased bone pain or spontaneous fracture occurred, and we consider that the risks of these complications are low if a course of treatment for three rather than six months is given.

Workers who have studied the effects of APD have used a range of doses. ${ }^{9}$ At doses similar to the one used in this study the pyrexia which may occur in the early stages of treatment was avoided, and the biochemical and clinical response appeared to be superior to those claimed for EHDP. ${ }^{10}$ However, the two drugs do not appear to have been studied simultaneously by other groups. In the present albeit modest series APD did not appear to be any more effective than EHDP. From the two patients studied it does not appear that a one-month course of either drug is satisfactory. These two patients had a modest fall in serum AP and urine HOP/creat, but relapse occurred as soon as the treatment was stopped. However, this disease, as judged by biochemical parameters was particularly severe in these patients, and a short course may be beneficial in some patients.

We recommend that the most effective regimen currently available in Britain is EHDP $20 / \mathrm{kg} /$ day given for three months. On this regimen all patients should respond. Those with less severe Paget's disease are likely to have a prolonged remission. Those with more severe disease are likely to relapse after a variable period. However, their biochemical parameters are still well below pretreatment levels nine months after stopping treatment. In these patients repeat courses of EHDP should be given, though a minimum of three months treatment-free period should probably be allowed to avoid the risks of osteomalacia. Further comparisons of the two drugs are justified, particularly for patients with severe Paget's disease, or who have failed to respond to one or other diphosphonate. In addition, the place of combinations of diphosphonates and calcitonin has also to be defined.

\section{References}

1 Dethridge F M, Guyer P B, Barker D J P. European distribution of Paget's disease of bone. Brt Med J 1982; 285: 1005-8.

2 MacIntyre I, Evans I M A, Hobitz H H G, Joplin G F, Stevenson J C. Chemistry, physiology and therapeutic applications of calcitonin. Arthritis Rheum 1980; 23: 1139-47. 
3 Francis M D, Russell R G G, Fleisch H. Diphosphonates inhibit formation of calcium phosphate crystals in vitro and pathological calcification in vivo. Science 1969; 165: 1264.

4 Fleisch H, Russell R G G, Francis M D. Diphosphonates inhibit hydroxyapatite dissolution in vitro and bone resorption in tissue culture and in vivo. Science 1969; 165: 1262-4.

5 Khairi M R A, Altman R D, De Rosa G P, Zimmerman J, Schenk R K, Johnston C C. Sodium etidronate in the treatment of Paget's disease of bone. Ann Intern Med 1977; 87: 656-63.

6 Siris E S, Canfield R E, Jacobs T P, Baquiran D C. Long-term therapy of Paget's disease of bone with EHDP. Arthritis Rheum 1980; 23: 1177-83.

7 Johnston C C, Khairi M R A, Meunier P J. Use of etidronate (EHDP) in Paget's disease of bone. Arthritis Rheum 1980; 23: $1172-6$.

8 Bijvoet O L M, Frijlink W B, Jie K, et al. APD in Paget's disease of bone. Arthritis Rheum 1980; 23: 1193-204.
9 Frijlink W B, Bijvoet O L M, te Velde J, Heynen G. Treatmen? of Paget's disease of bone with (3-amino-1-hydroxypropylidene 1,1-biphosphonate (APD). Lancet 1979; i: 799-803.

10 Heynen G, Delwaide P, Bijvoet O L M, Franchimonth PO Clinical and biological effects of low doses of (3-amino-10 hydroxypropylidene)-11-biphosphonate (APD) in Paget's dis $\overline{\bar{c}}$ ease of bone. Eur J Clin Invest 1982; 11: 29-35.

11 Douglas D L, Duckworth T, Russell R G G, et al. Effect ob dichloromethylane diphosphonate in Paget's disease of bone and in hypercalcaemia due to primary hyperparathyroidism of malignant disease. Lancet 1980 ; i: 1043-7.

12 Douglas D L, Duckworth T, Karis J A, et al. Biochemical and clinical responses to dichloromethylane diphosphonat $\vec{E}$ $\left(\mathrm{Cl}^{2} \mathrm{MDP}\right)$ in Paget's disease of bone. Arthritis Rheum 1980; 232 1185-92.

13 Delmas P D, Chaupy M C, Vignon S, et al. Long term effects of dichloromethylene diphosphonate in Paget's disease of bone. A Clin Endocrinol Metab 1982; 54: 837-44. 